\title{
Predicting body composition using foot-to-foot bioelectrical impedance analysis in healthy Asian individuals
}

\author{
Chun-Shien $\mathrm{Wu}^{1 \dagger}$, Yu-Yawn Chen ${ }^{2 \dagger}$, Chih-Lin Chuang ${ }^{3}$, Li-Ming Chiang ${ }^{4}$, Gregory B. Dwyer ${ }^{5}$, Ying-Lin Hsu' \\ Ai-Chun Huang ${ }^{7}$, Chung-Liang Lai ${ }^{8}$ and Kuen-Chang Hsieh ${ }^{9,10^{*}}$
}

\begin{abstract}
Background: The objectives of this study were to develop a regression model for predicting fat-free mass (FFM) in a population of healthy Taiwanese individuals using standing foot-to-foot bioelectrical impedance analysis (BIA) and to test the model's performance in predicting FFM with different body fat percentages (BF\%).

Methods: We used dual-energy X-ray absorptiometry (DXA) to measure the FFM of 554 healthy Asian subjects (age, 16-75 y; body mass index, $\left.15.8-43.1 \mathrm{~kg} / \mathrm{m}^{2}\right)$. We also evaluated the validity of the developed multivariate model using a double cross-validation technique and assessed the accuracy of the model in an all-subjects sample and subgroup samples with different body fat levels.

Results: Predictors in the all-subjects multivariate model included height ${ }^{2} /$ impedance, weight, year, and sex $\left(\right.$ FFM $=13.055+0.204$ weight +0.394 height $^{2} /$ Impedance -0.136 age +8.125 sex $($ sex: Female $=0$, Male $=1)$, $r^{2}=0.92$, standard error of the estimate $=3.17 \mathrm{~kg}$ ). The correlation coefficients between predictive FFM by BIA $\left(F_{F M}\right)$ and DXA-measured FFM (FFM DXA $)$ in female subjects with a total-subjects BF\% $30 \%-40 \%$ and $>40 \%$ were $r=0.87,0.90,0.91,0.89$, and 0.94 , respectively, with bias \pm 2 SD of $0.0 \pm 3.0 \mathrm{~kg},-2.6 \pm$ $1.7 \mathrm{~kg},-1.5 \pm 2.8 \mathrm{~kg}, 0.5 \pm 2.7 \mathrm{~kg}$, and $2.0 \pm 2.9 \mathrm{~kg}$, respectively. The correlation coefficients between FFM $\mathrm{BIA}_{\mathrm{A}}$ and FFM $_{\text {DXA }}$ in male subjects with a total-subjects BF\% DXA of $<10 \%, 10 \%-20 \%, 20 \%-30 \%$, and $>30 \%$ were $r=0.89$, $0.89,0.90,0.93$, and 0.91 , respectively, with bias $\pm 2 S D$ of $0.0 \pm 3.2 \mathrm{~kg},-2.3 \pm 2.5 \mathrm{~kg},-0.5 \pm 3.2 \mathrm{~kg}, 0.4 \pm 3.1 \mathrm{~kg}$, and $2.1 \pm 3.2 \mathrm{~kg}$, respectively.
\end{abstract}

Conclusions: The standing foot-to-foot BIA method developed in this study can accurately predict FFM in healthy Asian individuals with different levels of body fat.

Keywords: Dual-energy X-ray absorptiometry, Foot-to-foot, Cross-validation, Fat-free mass

\section{Background}

In recent years, bioelectrical impedance analysis (BIA) has undergone major changes. The traditional electrodes that are pasted on with gel have been replaced with reusable stainless steel contact electrodes [1,2], and the measuring position has been changed from supine to standing. In standing foot-to-foot BIA, impedance is

\footnotetext{
* Correspondence: abaqus0927@yahoo.com.tw

${ }^{\dagger}$ Equal contributors

${ }^{9}$ Office of Physical Education and Sport, National Chung Hsing University, 250 Kuo Kuang Rd., Taichung City 402, Taiwan

${ }^{10}$ Research Center, Charder Electronic Co., LTD, No. 103, Guozhong Rd., Dali Dist., Taichung City 412, Taiwan

Full list of author information is available at the end of the article
}

measured through the electronic pathway of the lower extremities [3]. This technique is widely used to assess the whole-body composition [4-6].

Although many fat-free mass (FFM) predictive models based on BIA performed in the supine position have been validated, most of these models have been developed for Caucasian, African-American, Hispanic, and Native American populations [7-9]. Insufficient research has been performed to develop FFM predictive models based on BIA in Asian populations. Because different ethnic groups may exhibit different body composition characteristics, predictive models should be developed for specific 
populations to prevent ethnic bias and facilitate accurate estimates of FFM [10, 11].

Standing foot-to-foot BIA may be a convenient and safe method for assessing body composition. In the existing research, however, there is inconsistent support of the validity of BIA in estimating FFM in the general population $[4,6,8,12-17]$, BIA cannot accurately estimate FFM in obese populations [18-20], BIA tends to underestimate the body fat percentage (BF\%) and overestimate the FFM, and body composition parameters are affected by the $\mathrm{BF} \%$ in tested subjects.

Studies to date have only explored the regression mode for tested subjects because manufacturers retain the prediction equations of the measuring system as confidential information; therefore, knowledge of BIA devices is limited [13]. Additionally, studies to date have had relatively small sample sizes that do not represent the entire population, thereby minimizing the generalizability and external validity of the results.

\section{Methods \\ Subjects}

In total, 554 Taiwanese subjects were recruited by advertisement and volunteered to participate in this study. The subjects were asked to complete a health questionnaire that included personal background information, physical characteristics, and health status. The subjects were tested following $48 \mathrm{~h}$ without alcohol, 7 days without diuretic agents, and $24 \mathrm{~h}$ without strenuous physical activity. No urination was allowed within $30 \mathrm{~min}$ prior to the BIA and DXA measurements. Female participants were not tested during their menses. No subjects reported a history of endocrine, nutritional, or growth disorders; chronic illnesses such as high blood pressure, diabetes, cancer, kidney dysfunction, liver disease, or asthma; or electronic device insertion. Each subject underwent footto-foot BIA and DXA at the Department of Radiology of Dah Li County Jen-Ai Hospital in Taiwan. This study was approved by the institutional review board of Jen-Ai Hospital.

\section{Anthropometry}

The subjects were weighed to the nearest $0.1 \mathrm{~kg}$ on a Weight-Tronix scale, (Scale Electronics Development, NY, USA). Height was measured without shoes to the nearest $0.5 \mathrm{~cm}$ on a stadiometer (Holtain Ltd., Crosswell, Wales, UK). Body mass index (BMI) was calculated as weight divided by height squared $\left(\mathrm{kg} / \mathrm{m}^{2}\right)$.

\section{Measurements of body composition}

The subjects were asked to wear a cotton gown and remove all metallic objects from the body. Body composition was measured using a DXA system (Lunar Prodigy; GE Healthcare, Madison, WI, USA). The estimation of body composition included measurement of total body fat, fat-free soft tissue, and bone mineral content. The $\mathrm{BF} \%$ was calculated as $100 \times$ fat mass /(fat mass $+\mathrm{FFM})$, where FFM was the summation of the fat-free soft tissue and mineral content. The DXA measurements were taken at 2:00 PM using enCORE 2003 Version 7.0 software (GE Healthcare), and the foot-to-foot impedance measurements were conducted following the DXA measurements. With the subjects in a standing position, the measurements were repeated until they were stable to within $5 \mathrm{ohm}$ (usually up to three times within an interval of $30 \mathrm{~s}$ ), and the average value of three repeated measurements was used in the calculations.

\section{Impedance analysis}

The BIA measurements were taken using the impedance measurement device. We used an imbedded stainless steel contact plate with four electrodes, which was connected to a QuadScan 4000 (Bodystat, Douglas, UK). The QuadScan 4000 was in turn connected to stainless steel electrode plates. A body composition sensing platform (HBF-361; Omron Healthcare, Kyoto, Japan) was used as the impedance measuring base and included a stainless steel polar plate and cable. The subjects were asked to stand on the contact plate without shoes and with their feet slightly apart. A current of only $50 \mathrm{kHz}$ was used to measure the impedance in the left-foot-toright-foot pathway, expressed as $\mathrm{Z}_{\mathrm{F}-\mathrm{F}}$.

The coefficient of variation (CV) (standard deviation $[\mathrm{SD}] /$ mean), expressed as a percentage, of the within-day and between-day estimates of impedance in all subjects was calculated to evaluate the repeatability of the impedance measurements. After referring to the amount of time spent during the DXA measurement, the subjects lay in the supine position for $20 \mathrm{~min}$ and then underwent the foot-to-foot standing position impedance measurement. The within-day $\mathrm{CV}$ was calculated by measuring the impedance of ten subjects (five males and five females) ten times within $1 \mathrm{~h}$, and the between-day $\mathrm{CV}$ was calculated by measuring the impedance of 10 subjects on five consecutive days.

All measurements were conducted in a well-ventilated room with controlled temperature and humidity. The impedance measurements were performed three times within $3 \mathrm{~min}$ in each subject immediately after the DXA measurements.

\section{Statistical analysis}

The BF\% derived by DXA (expressed as $\mathrm{BF} \%_{\mathrm{DXA}}$ ) was grouped by $10 \%$ difference intervals for percent body fat [21]. The variables, which included age, height, weight, $\mathrm{BMI}$, and impedance, are expressed as mean $\pm \mathrm{SD}$, and the numbers in parentheses are the minimum and maximum 
values. The paired-samples $t$-test was used to evaluate the differences between the two measurement methods.

The estimates of FFM derived by DXA were used as reference values (expressed as FFM $_{\mathrm{DXA}}$ ) to develop a stepwise multiple regression model by setting height squared/impedance $\left(\mathrm{h}^{2} / \mathrm{Z}_{\mathrm{F}-\mathrm{F}}\right)$, weight $(\mathrm{w})$, age $(\mathrm{y})$, and sex (s, female: 0 , male: 1 ) as predictive variables. The stepwise procedure included the variable with the highest correlation coefficient and the minimum standard error of estimation in the model first. The FFM model predicted by BIA was developed using a double crossvalidation technique. The subjects were split into two groups, $G_{1}$ and $G_{2}$, based on $B F \%$. Thus, the two groups were evenly matched for BF\%. An FFM predictive model was then constructed for each group and cross-validated with each model. If the FFM predictive models were proved to be similar to each other by comparing the correlation and standard error of the estimate (SEE) [11], the two samples were combined to develop a pooled FFM predictive model [22, 23].

Furthermore, the root mean square error (RMSE) and pure error (PE) were used to test the accuracy of the FFM predictive model by BIA:

$$
\mathrm{RMSE}=\sqrt{\sum \frac{\left(\mathrm{y}_{\mathrm{i}}^{\prime}-\mathrm{y}_{\mathrm{i}}\right)^{2}}{\mathrm{n}}-\mathrm{p}-1,}
$$

where $\mathrm{y}^{\prime}$ the predicted FFM, $\mathrm{y}$ is the observed FFM, $\mathrm{n}$ is the number of subjects, and $\mathrm{p}$ is the number of predictor variables, and

$$
\mathrm{PE}=\sqrt{\sum \frac{\left(\mathrm{y}_{\mathrm{i}}^{\prime}-\mathrm{y}_{\mathrm{i}}\right)^{2}}{\mathrm{n}},}
$$

where the error of measurement estimates the magnitude of the error for a given measurement and is defined as the difference between measurements for the individual (i) ( $\mathrm{i}=1 \ldots, n$, where $\mathrm{n}$ is the number of individuals).

A Bland-Altman plot [24] was performed to assess the agreement between the results from the FFM predictive model and the DXA measurements. Passing-Bablok regression describes a linear regression procedure with no special assumptions regarding the distribution of the samples and the measurement errors [25] and was used to evaluate the interchangeability of the two methods. All analyses were conducted using SPSS for Windows (Version 17.0; SPSS Inc., Chicago, IL, USA) and MedCalc (Version 9.0; MedCalc Inc., Mariakerke, Belgium). Statistical significance was set at $p<0.05$ for all tests.

\section{Results}

The physical characteristics of the subjects grouped by sex and $\mathrm{BF} \%$ are shown in Table 1. A total of 554 subjects met the criteria for this study: 257 females and 297 males. The subjects ranged in age from 16 to 75 years with a mean of $32.8 \pm 14.8$ years. Their weight varied from 39.0 to $125.5 \mathrm{~kg}$, and their BMI ranged from 15.9 to $43.1 \mathrm{~kg} / \mathrm{m}^{2}$ with a mean of $24.0 \pm 4.1 \mathrm{~kg} / \mathrm{m}^{2}$. The BMIs for $G_{1}$ and $G_{2}$ were $23.9 \pm 4.2$ (range, 16.0-43.1) and $24.0 \pm 4.1$ (range, $16.2-42.9) \mathrm{kg} / \mathrm{m}^{2}$, respectively. The subjects were also divided into five different subgroups by $10 \%$ body fat intervals (Table 1).

The CV of the within-day estimates of impedance in ten subjects was $0.3 \%$ to $0.8 \%$, and the $\mathrm{CV}$ of the between-day estimates of impedance in 10 subjects was $0.9 \%$ to $1.7 \%$.

Table 2 summarizes the cross-validation results in which the $r^{2}$, SE, PE, and RMSE show very similar values between the two groups. The regression lines of FFM $_{\text {BIA }}$ against $F_{F M} M_{D X A}$ developed using $G_{1}$ and $G_{2}$ data demonstrate similar trends deviated from the identical line (slope $=0.92$ for $\mathrm{G}_{1}$ and 0.93 for $\mathrm{G}_{2}$ ).

The results of the FFM predictive model by multiple regression analysis for all 554 subjects are shown in Table 3. Figure 1a shows the correlation for all subjects measured by $\mathrm{FFM}_{\mathrm{DXA}}$ and the predictive values of $\mathrm{FFM}_{\mathrm{BIA}}$. The Passing-Bablok regression analysis indicated a foot-to-foot BIA and DXA equation as follows: $\mathrm{FFM}_{\mathrm{BIA}}=0.911 \mathrm{FFM}_{\mathrm{DXA}}+4.27$ with a $95 \%$ confidence interval (CI) of 0.80 to 1.02 for the slope and a $95 \% \mathrm{CI}$ of -0.74 to 9.28 for the intercept of the regression model, indicating that the foot-to-foot BIA and DXA FFM estimate methods are interchangeable $(p>0.10)$. Figure 1b shows a Bland-Altman plot of the differences between the all-subjects FFM $_{\mathrm{DXA}}$ and the predictive values of $F_{F M}$ BIA. For FFM, the -2 SD to +2 SD was -6.40 to $6.40 \mathrm{~kg}$. The correlation between $\mathrm{FFM}_{\mathrm{BIA}}-\mathrm{FFM}_{\mathrm{DXA}}$ and FFM $_{\mathrm{DXA}}$ can be expressed as the regression line $\mathrm{y}=-0.089 x+4.428(\mathrm{r}=0.31, p<0.001)$.

In the developed FFM predictive model, the cumulative SEE and $r^{2}$ by individual predictors are shown in Table 4 . The determination coefficient between the predictive FFM by the single predictor $\mathrm{h}^{2} / \mathrm{Z}_{\mathrm{F}-\mathrm{F}}$ and $\mathrm{FFM}_{\mathrm{DXA}}$ was $\mathrm{r}^{2}=$ 0.837 . As the predictors sex, weight, and age were added into the model, the determination coefficients changed to $r^{2}=0.881,0.893$, and 0.922 , respectively. The standard $\beta$ coefficients of the predictors' height squared/impedance, sex, weight, and age were $0.43,0.36,0.25$, and -0.18 , respectively, and the variance inflation factor (VIF) values were $4.27,2.25,2.49$, and 1.16 , respectively.

Table 5 shows a comparison of the results for the mean and bias. The regression line and correlation coefficients between $F M_{\text {DXA }}$ and $F_{F M}$ BIA predicted by the model for sex and BF\% are shown in Table 5. The correlation coefficients of different $\mathrm{BF} \%_{\mathrm{DXA}}$ subgroups ranged from 0.89 to $0.94(\mathrm{r}=0.89-0.94)$. The subgroups with the largest bias \pm SD of $F_{F M}$ and $F_{\text {DFA }}$ aIA were the $\mathrm{BF} \%_{\text {DXA }}>40 \%$ (female subgroup) and the $\mathrm{BF} \%_{\text {DXA }}>30 \%$ 
Table 1 Characteristics and impedances of subjects grouped by sex and \%BF

\begin{tabular}{|c|c|c|c|c|c|}
\hline \multicolumn{6}{|l|}{ Female $(n=257)$} \\
\hline BF\% ${ }_{D X A}$ & $<20 \%(n=22)$ & $20 \%-30 \%(n=80)$ & $30 \%-40 \%(n=94)$ & $>40 \%(n=61)$ & Total $(n=257)$ \\
\hline \multirow[t]{2}{*}{ Age(year) } & $21.6 \pm 3.8$ & $27.9 \pm 12.5$ & $37.5 \pm 13.4$ & $43.3 \pm 15.4$ & $34.7 \pm 14.8$ \\
\hline & $(17,59)$ & $(16,61)$ & $(16,67)$ & $(18,75)$ & $(16,75)$ \\
\hline \multirow[t]{2}{*}{ Height(cm) } & $162.8 \pm 6.8$ & $162.1 \pm 6.3$ & $158.9 \pm 6.4$ & $158.9 \pm 7.6$ & $160.2 \pm 6.9$ \\
\hline & $(151,174)$ & $(148,174)$ & $(143,181)$ & $(144,178)$ & $(143,181)$ \\
\hline \multirow[t]{2}{*}{ Weight(kg) } & $49.3 \pm 4.0$ & $54.8 \pm 6.3$ & $58.3 \pm 8.0$ & $74.8 \pm 14.5$ & $60.2 \pm 12.2$ \\
\hline & $(44,58)$ & $(39,69)$ & $(42,84)$ & $(53,108)$ & $(38,108)$ \\
\hline \multirow[t]{2}{*}{ BMI $\left(\mathrm{kg} / \mathrm{m}^{2}\right)$} & $18.9 \pm 1.3$ & $20.8 \pm 2.0$ & $23.1 \pm 2.9$ & $29.1 \pm 4.5$ & $23.5 \pm 4.5$ \\
\hline & $(16,22)$ & $(16,25)$ & $(16,31)$ & $(22,43)$ & $(16,43)$ \\
\hline \multirow[t]{2}{*}{$Z_{F-F}(o h m)$} & $560.5 \pm 76.0$ & $529.2 \pm 60.2$ & $443.9 \pm 58.2$ & $488.9 \pm 68.0$ & $521.5 \pm 66.1$ \\
\hline & $(446,733)$ & $(391,704)$ & $(326,595)$ & $(362,706)$ & $(326,733)$ \\
\hline \multirow[t]{2}{*}{$\mathrm{h}^{2} / \mathrm{Z}_{\mathrm{F}-\mathrm{F}}\left(\mathrm{cm}^{2} / \mathrm{ohm}\right)$} & $48.1 \pm 7.0$ & $50.4 \pm 7.1$ & $48.4 \pm 6.3$ & $52.6 \pm 8.1$ & $50.0 \pm 7.2$ \\
\hline & $(33,59)$ & $(36,69)$ & $(33,65)$ & $(33,79)$ & $(33,79)$ \\
\hline \multicolumn{6}{|l|}{ Male $(n=297)$} \\
\hline BF\% $\%_{D X A}$ & $<10 \%(n=46)$ & $10 \%-20 \%(n=96)$ & $20 \%-30 \%(n=104)$ & $>30 \%(n=51)$ & Total $(n=297)$ \\
\hline \multirow[t]{2}{*}{ Age(year) } & $20.3 \pm 2.3$ & $24.7 \pm 10.7$ & $35.4 \pm 14.8$ & $44.7 \pm 14.6$ & $31.2 \pm 14.8$ \\
\hline & $(16,29)$ & $(16,65)$ & $(16,71)$ & $(21,71)$ & $(16,71)$ \\
\hline \multirow[t]{2}{*}{ Height(cm) } & $173.0 \pm 5.7$ & $173.5 \pm 8.1$ & $173.2 \pm 6.7$ & $172.3 \pm 8.0$ & $173.3 \pm 7.3$ \\
\hline & $(160,182)$ & $(157,196)$ & $(156,193)$ & $(155,200)$ & $(155,200)$ \\
\hline \multirow[t]{2}{*}{ Weight(kg) } & $65.0 \pm 5.4$ & $67.3 \pm 8.1$ & $76.4 \pm 10.4$ & $86.5 \pm 14.5$ & $73.4 \pm 12.4$ \\
\hline & $(52,77)$ & $(42,90)$ & $(59,122)$ & $(66,125)$ & $(42,125)$ \\
\hline \multirow[t]{2}{*}{ BMI $\left(\mathrm{kg} / \mathrm{m}^{2}\right)$} & $21.7 \pm 1.6$ & $22.3 \pm 1.9$ & $25.4 \pm 2.7$ & $28.8 \pm 4.1$ & $24.4 \pm 3.7$ \\
\hline & $(18,26)$ & $(17,27)$ & $(19.7,37)$ & $(23,42)$ & $(17,42)$ \\
\hline \multirow[t]{2}{*}{$Z_{F-F}(o h m)$} & $441.3 \pm 38.3$ & $451.5 \pm 46.8$ & $449.8 \pm 53.9$ & $439.9 \pm 49.9$ & $447.3 \pm 48.8$ \\
\hline & $(380,530)$ & $(365,685)$ & $(334,625)$ & $(345,572)$ & $(335,685)$ \\
\hline \multirow[t]{2}{*}{$\mathrm{h}^{2} / \mathrm{Z}_{\mathrm{F}-\mathrm{F}}\left(\mathrm{cm}^{2} / \mathrm{ohm}\right)$} & $68.4 \pm 7.3$ & $67.4 \pm 8.4$ & $67.8 \pm 10.1$ & $69.2 \pm 10.0$ & $68.0 \pm 9.1$ \\
\hline & $(56,84)$ & $(36,96)$ & $(46,97)$ & $(49,96)$ & $(36,97)$ \\
\hline
\end{tabular}

${ }^{\mathrm{a}}$ All values are mean $\pm \mathrm{SD}$; minimum and maximum in parentheses, ${ }^{2} \mathrm{Bl}$, bioelectrical index; $\mathrm{h}^{2} / \mathrm{Z}_{\mathrm{F}-\mathrm{F}}$, Height ${ }^{2} / \mathrm{Impedance}$

(male subgroup), with bias \pm SD of $-2.0 \pm 2.9 \mathrm{~kg}$ and $2.1 \pm$ $3.2 \mathrm{~kg}$, respectively. The subgroups with the smallest bias \pm SD of FFM ${ }_{\text {DXA }}$ and FFM BIA $_{\text {a }}$ were the female subgroup and the male subgroup, with bias \pm SD of $0.0 \pm$ $3.0 \mathrm{~kg}$ and $0.0 \pm 3.2 \mathrm{~kg}$, respectively. Although the Bland-Altman plot indicates that there was a systematic error with the BIA method, this error was small. For example, the BIA method would underestimate FFM by an average of $2.2 \%$ in an individual with an FFM of $40 \mathrm{~kg}$ and overestimate FFM by $-1.5 \%$ in an individual with an FFM of $60 \mathrm{~kg}$.

\section{Discussion}

The present study measured FFM in 544 healthy Asian individuals using DXA (297 male, 257 female; age range, 16-75 years). We used BIA to measure the impedance at $50 \mathrm{kHz}$ of the lower extremities in a standing position to develop a multivariable model for predicting FFM using DXA measurements. We also evaluated the validity of the developed multivariable model with a double cross-validation technique and assessed the accuracy of the model in an all-subjects sample and in different BF\% subgroup samples. The results of the study indicated that the FFM predictive model based on BIA estimates is a valid method for assessing FFM in healthy subjects with different $\mathrm{BF} \%$ values. The force of gravity has an effect on the fluid distribution in our body. Depending on the body position, gravity may also cause differences in blood pressures. As a result, regulation of blood volume may become challenging: standing still leads to rapid and persistent plasma volume loss of up to $7 \%$ for a 30 min period [26]. Nunez et al. [1] performed foot-to-foot standing upright and supine position impedance measurements and obtained the following results. There was a high correlation between upright and supine position impedance measurements of the lower extremities. The 
Table 2 Prediction equation for $G_{1}$ and $G_{2}$ subjects

\begin{tabular}{|c|c|}
\hline \multicolumn{2}{|l|}{$\mathrm{G}_{1}$ subjects $(n=277)$} \\
\hline Measured FFM & $50.54 \pm 11.58 \mathrm{~kg}$ \\
\hline Prediction FFM & $\begin{array}{l}12.518+0.215 \mathrm{w}+0.397 \mathrm{~h}^{2} / Z_{\mathrm{F}-\mathrm{F}}-0.143 \mathrm{y}+7.843 \mathrm{~S}(\text { Female }=0, \text { Male }=1),\left(\mathrm{r}^{2}=0.92, \mathrm{SE}=3.23 \mathrm{~kg}\right. \\
\mathrm{CV}=6.3 \%)(1 . \mathrm{a})\end{array}$ \\
\hline \multicolumn{2}{|l|}{ Prediction FFM } \\
\hline Cross-validation using $\mathrm{G}_{2}$ subjects FFM & $50.48 \pm 10.97 \mathrm{~kg}, \mathrm{r}=0.96$, bias $\pm \mathrm{SD}=-0.06 \pm 3.22 \mathrm{~kg}, \mathrm{PE}=3.22 \mathrm{~kg}, \mathrm{RMSE}=2.31 \mathrm{~kg}, \mathrm{LOA}=-6.46$ to $6.38 \mathrm{~kg}$ \\
\hline \multicolumn{2}{|l|}{$\mathrm{G}_{2}$ subjects $(n=277)$} \\
\hline Measured FFM & $49.81 \pm 10.91 \mathrm{~kg}$ \\
\hline Prediction FFM BIA & $\begin{array}{l}13.639+0.192 \mathrm{~W}+0.392 \mathrm{~h}^{2} / Z_{\mathrm{F}-\mathrm{F}}-0.129 \mathrm{y}+8.355 \mathrm{~S}(\text { Female }=0, \text { Male }=1),\left(\mathrm{r}^{2}=0.92, \mathrm{SEE}=3.13 \mathrm{~kg},\right. \\
\mathrm{CV}=6.1 \%)(1 . \mathrm{b})\end{array}$ \\
\hline \multicolumn{2}{|l|}{ Prediction FFM } \\
\hline Cross-validation using $\mathrm{G}_{1}$ subjects FFM & $49.86 \pm 10.60 \mathrm{~kg}, \mathrm{r}=0.96$, bias $\pm S D=0.05 \pm 3.13 \mathrm{~kg}, P E=3.12 \mathrm{~kg}, \mathrm{RMSE}=2.18 \mathrm{~kg}, \mathrm{LOA}=-6.21$ to $6.31 \mathrm{~kg}$ \\
\hline
\end{tabular}

difference in impedance measured by the two methods versus the mean impedance for the two methods was evaluated as a Bland-Altman plot $(\mathrm{r}=0.44, p=0.23$, NS). The plot showed a small but systematic difference between the two methods. In a study by Rush et al. [27], the foot-to-hand impedance decreased by up to $9 \mathrm{ohm}$ (mean, $5 \mathrm{ohm} ; 1.0 \%$ ) over $10 \mathrm{~min}$ of standing and increased by up to $7 \mathrm{ohm}$ (mean, $3 \mathrm{ohm} ; 0.7 \%$ ) in the lying position. Based on the results of both studies, the difference in the impedance measures was caused by the changes in the effects of gravity on the different positions and body fluids. Oshima [28] reported that the average foot-to-foot impedance value would decrease by $6.8 \%$ after $6 \mathrm{~h}$ of continuous measurements. Kushner et al. [29] also reported a $-3 \%$ to $1 \%$ change during a 5-min standing upright position and 10-min supine position in hand-to-foot impedance measurements. In the present study, regardless of standing or lying down, only a $1 \%$ decrease in the foot-to-foot impedance measurement occurred over a 3-min period (data not shown).

The standing foot-to-foot BIA method described herein produced inconclusive results. The present study had the following characteristics: (a) We used the same instruments in the same setting to measure the impedance by foot-to-foot BIA in the standing position and FFM by DXA in a large, single-institution Asian sample; such patients have been insufficiently studied in BIA research to date. (b) Instead of evaluating the validity of existing commercial instruments, this study aimed to develop an FFM predictive model using standing footto-foot BIA. (c) This study tested not only the accuracy and suitability of BIA for assessing body composition in a general population, but also its performance in subjects with different $\mathrm{BF} \%$ values.

The present study used $\mathrm{h}^{2} / \mathrm{Z}_{\mathrm{F}-\mathrm{F}}$ and other anthropometric variables, such as weight, sex, and age, as predictive variables to develop the prediction model. We used $h^{2} / Z_{F-F}$ instead of $h^{2} /$ reactance $\left(X_{C}\right)$ or resistance $(R)$, as adopted by other studies [23, 30], as a predictor in the regression model for the following reasons: The QuadScan 4000 produces a $50-\mathrm{kHz}$ frequency and provides measured results for resistance, impedance, and reactance. Nunez et al. [1] proposed a standing foot-to-foot bioimpedance analysis FFM estimate model in which they used Z (impedance) as

Table 3 Prediction equation for FFM using all subjects

\begin{tabular}{ll}
\hline Development group $(n=554)$ & \\
\hline Measured FFM DXA & $50.17 \pm 11.25 \mathrm{~kg}$ \\
FFM prediction equation $\left(F F M_{B I A}\right)$ & $13.055+0.204 \mathrm{~W}+0.394 \mathrm{~h}^{2} / \mathrm{Z}_{\mathrm{F}-\mathrm{F}}-0.136 \mathrm{y}+8.125 \mathrm{~S}(\mathrm{Female}=0, \mathrm{Male}=1),\left(\mathrm{r}^{2}=0.92, \mathrm{SEE}=3.17 \mathrm{~kg}, \mathrm{CV}=6.3 \%\right)(2)$ \\
Prediction FFM & $50.17 \pm 10.69 \mathrm{~kg}, \mathrm{PE}=3.20 \mathrm{~kg}, \mathrm{RMSE}=2.29 \mathrm{~kg}$ \\
\hline
\end{tabular}

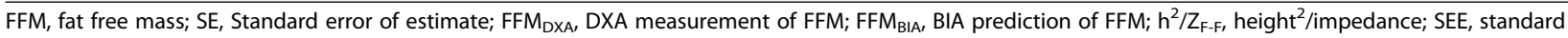
error of estimate;

Root mean square error (RMSE) $=\sqrt{\sum \frac{\left(y_{i}^{\prime}-y_{i}\right)^{2}}{n}-p-1}$

Pure errors $(P E)=\sqrt{\sum \frac{\left(y_{i}^{\prime}-y_{i}\right)^{2}}{n}}$; where $y^{\prime}$ is the predicted FFM, $y$ is the observed, $n$ is the number of subjects and $p$ is the number of predictor variables 


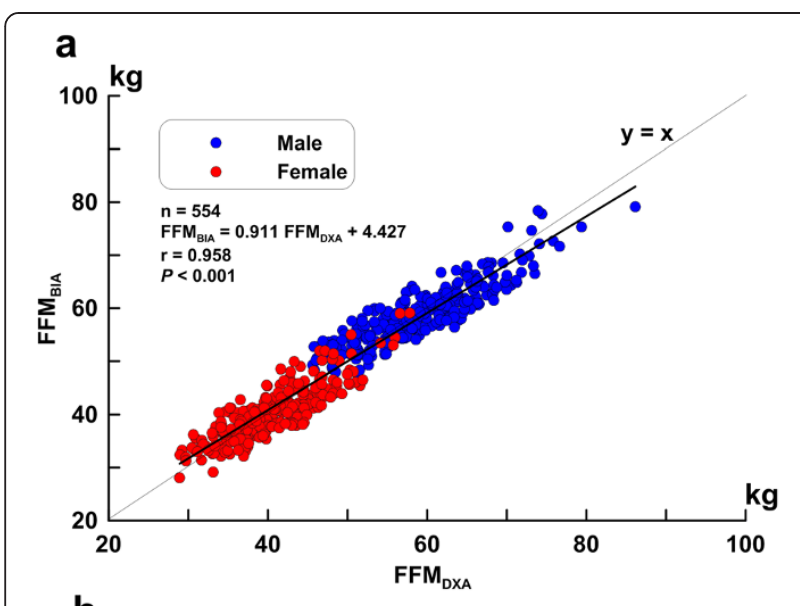

b

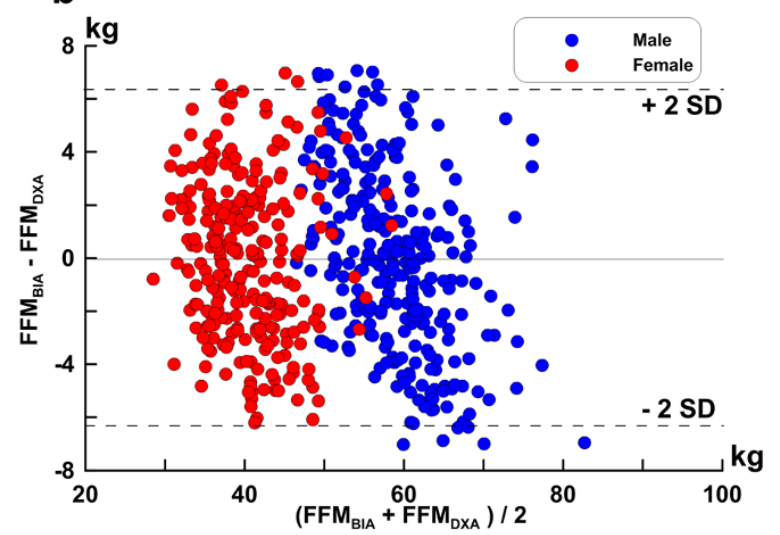

Fig. 1 Correlations (a) and difference (b) of FFM in all subjects estimated by FFM $M_{D X A}$ and FFM $M_{B I A}$. The difference (calculated as FFM BIA $_{\text {- FFM }}$ DXA per Bland-Altman) is plotted against the mean of the measurements of FFMDXA and FFM $M_{\text {BIA }}$

the estimate variable; this variable has also been widely used in other studies of BIA standing-position body composition estimation [31]. Furthermore, in similar research, Kotler [32] and Lukaski et al. [33] indicated that when using resistance or impedance estimating FFM, TBW (total body water) and TBK (total body potassium) have no significant difference. For these reasons, we used impedance as the estimated variable. When developing a body composition predictive model, the predictors should be easy to measure, accurate, reproducible, and physiologically related to the dependent variable $[34,35]$; the predictors in our model meet these requirements $[36,37]$.

When developing a regression model, the following issues should be taken into consideration to avoid violating assumptions and to ensure that the regression analyses have sufficient power: collinearity, sample size, number of predictors, cross-validation, and SEE [38]. When additional variables were added into the FFM predictive equation using BIA and other anthropometric variables, collinearity was present if the predictive variables were highly correlated. This might affect the estimation of the regression coefficient in a predictive model, which may lead to incorrect identification of the predictive variables. The VIF analysis was conducted to identify potential problems related to collinearity. When the VIF of the predictors had exceeded ten, the collinearity was considered to be severe. In this study, the VIF was smaller than five; thus, collinearity did not exist.

To ensure sufficient power, the minimum sample size was set to 91 when the effect size was medium, the number of predictors was five, the power was 0.8 , and the alpha value was 0.05 [39]. When the effect size was small, the minimum sample size was 686. Although the number of subjects in the present study was less than 686 , the sample was large enough to minimize variable inflation and improve reliability. Additionally, a crossvalidated technique was used to validate the prediction model. In this study, height ${ }^{2} /$ impedance, sex, weight, and age were the predictors in the regression model. In the model, the correlation coefficient of height ${ }^{2} /$ impedance and $F_{\text {DXA }}$ was 0.92 , and the standardized coefficient $\beta$ was 0.43 ; these values explain approximately $43 \%$ of the variance of FFM. The prediction model developed using the $G_{1}$ and $G_{2}$ data was double cross-validated with an RMSE of 2.31 and $2.18 \mathrm{~kg}$, respectively and a bias \pm SD of $-0.01 \pm 3.22$ and $0.05 \pm 3.12 \mathrm{~kg}$, respectively. The similar results derived by the $G_{1}$ and $G_{2}$ models indicate that the predictive models can accurately predict FFM. The allsubjects predictive model also showed results similar to the $G_{1}$ and $G_{2}$ models in terms of the correlation coefficient, SEE, and CV, thus validating the accuracy of the predictive model. We also randomly assigned subjects into two groups to double cross-validate the regression models.

Table 4 Multiple stepwise regression analysis results for $h^{2} / Z_{F-F}$ measured with foot-to-foot BIA as an independent variable and FFM $M_{D X A}$ as a dependent variable

\begin{tabular}{|c|c|c|c|c|c|c|c|c|c|c|}
\hline \multicolumn{7}{|c|}{ Dependent variables used in model (All subjects, $n=554$ ) } & \multicolumn{4}{|c|}{ Dependent variable } \\
\hline$h^{2} / Z_{F-F}$ & Sex & Weight & Age & Intercept & SEE(kg) & $r^{2}$ & VIF & $\beta$ & r & SEE (kg) \\
\hline $0.84 \pm 0.02^{* *}$ & - & - & - & $-0.10 \pm 0.96$ & 4.54 & 0.84 & 4.27 & 0.43 & $0.92^{* *}$ & 4.54 \\
\hline $0.63 \pm 0.02^{* *}$ & $6.99 \pm 0.49^{* *}$ & - & - & $8.68 \pm 1.03^{* *}$ & 3.88 & 0.89 & 2.25 & 0.36 & $0.82^{* *}$ & 6.52 \\
\hline $0.52 \pm 0.03^{* *}$ & $7.56 \pm 0.47^{* *}$ & $0.14 \pm 0.02^{* *}$ & - & $7.09 \pm 0.99^{* *}$ & 3.68 & 0.90 & 2.49 & 0.25 & $0.73^{* *}$ & 7.74 \\
\hline $0.39 \pm 0.02^{* *}$ & $8.12 \pm 0.41^{* *}$ & $0.20 \pm 0.02^{* *}$ & $-0.14 \pm 0.01^{* *}$ & $13.05 \pm 0.96^{* *}$ & 3.16 & 0.92 & 1.16 & -0.18 & $-0.29^{* *}$ & 10.76 \\
\hline
\end{tabular}

Regression coefficient estimate $\pm \mathrm{SE} ; \mathrm{r}$, variance; $\mathrm{r}^{2}$, determination coefficient; ${ }^{*} p<0.05,{ }^{* *} p<0.001$; $\beta$ : Standardized coefficients; VIF, variance inflation factor 
Table 5 Comparison of the results of FFM DXA and FFM $_{\text {BIA }}$ for different \%BF subgroups ${ }^{a}$

\begin{tabular}{|c|c|c|c|c|c|}
\hline Female: BF\% ${ }_{D X A}$ & $<20 \%(n=20)$ & $20 \%-30 \%(n=80)$ & $30 \%-40 \%(n=94)$ & $>40 \%(n=61)$ & Total $(n=257)$ \\
\hline \multirow[t]{2}{*}{$F F M_{D X A}(k g)$} & $41.8 \pm 3.8$ & $41.8 \pm 5.2$ & $38.4 \pm 4.7$ & $40.9 \pm 6.9$ & $40.3 \pm 5.6$ \\
\hline & $(35,48)$ & $(29,52)$ & $(29,51)$ & $(30,58)$ & $(29,58)$ \\
\hline \multirow[t]{2}{*}{$\mathrm{FFM}_{\mathrm{BIA}}(\mathrm{kg})$} & $39.2 \pm 3.6$ & $40.3 \pm 4.7$ & $38.9 \pm 4.4$ & $42.9 \pm 6.7$ & $40.3 \pm 5.2$ \\
\hline & $(32,45)$ & $(29,51)$ & $(28,51)$ & $(31,60)$ & $(28,59)$ \\
\hline Bias $\pm S D^{b}(k g)$ & $-2.6 \pm 1.7$ & $-1.5 \pm 2.8$ & $0.5 \pm 2.7$ & $2.0 \pm 2.9$ & $0.0 \pm 3.0$ \\
\hline$r^{c}$ & 0.90 & 0.91 & 0.89 & 0.94 & 0.87 \\
\hline$p^{d}$ & $0.04^{*}$ & 0.06 & 0.43 & 0.11 & 0.92 \\
\hline Slope,e & 0.86 & 0.83 & 0.79 & 0.89 & 0.79 \\
\hline Intercept $\mathrm{t}^{\mathrm{e}}$ & 3.17 & 5.34 & 9.77 & 6.70 & 8.41 \\
\hline Male: BF\%DXA & $<10 \%(n=46)$ & $10 \%-20 \%(n=96)$ & $20 \%-30 \%(n=104)$ & $>30 \%(n=51)$ & Total $(n=297)$ \\
\hline \multirow[t]{2}{*}{$F_{F M_{D X A}}(k g)$} & $60.9 \pm 5.2$ & $58.6 \pm 7.0$ & $58.2 \pm 7.9$ & $57.9 \pm 7.7$ & $50.1 \pm 11.4$ \\
\hline & $(47,71)$ & $(33,76)$ & $(46,86)$ & $(46,77)$ & $(33,86)$ \\
\hline \multirow[t]{2}{*}{$\mathrm{FFM}_{\mathrm{BIA}}(\mathrm{kg})$} & $58.6 \pm 3.8$ & $58.1 \pm 5.3$ & $58.6 \pm 6.7$ & $60.0 \pm 7.4$ & $50.0 \pm 10.9$ \\
\hline & $(52,67)$ & $(39,74)$ & $(48,79)$ & $(47,79)$ & $(40,79.2)$ \\
\hline Bias $\pm S D^{b}(k g)$ & $-2.3 \pm 2.5$ & $-0.5 \pm 3.2$ & $0.4 \pm 3.1$ & $2.1 \pm 3.2$ & $0.0 \pm 3.2$ \\
\hline$r^{c}$ & 0.89 & 0.90 & 0.93 & 0.91 & 0.89 \\
\hline$p^{d}$ & $0.02^{*}$ & 0.59 & 0.68 & 0.16 & 0.97 \\
\hline Slope $e^{e}$ & 0.65 & 0.68 & 0.79 & 0.87 & 0.70 \\
\hline Intercept $^{\mathrm{e}}$ & 19.13 & 18.52 & 12.71 & 9.60 & 17.41 \\
\hline
\end{tabular}

${ }^{\mathrm{a}}$ All values are mean $\pm \mathrm{SD}$; minimum and maximum in parentheses

${ }^{b}$ The biases and standard deviations between FFM $M_{D X A}$ and FFM ${ }_{B I A}$ indifferent subgroups

${ }^{\mathrm{C}}$ The correlation coefficients of FFM $\mathrm{DXX}_{\mathrm{DA}}$ and FFM $_{\mathrm{BIA}}$ in different subgroups

${ }^{\mathrm{d}}$ The results of paired $t$-tests between FFM $\mathrm{DXA}_{\mathrm{B}}$ and $\mathrm{FFM}_{\mathrm{BIA}}$ indifferent subgroups

${ }^{\mathrm{e}}$ The slopes and intercepts of the regression model of FFM $\mathrm{DXX}_{\mathrm{A}}$ and $\mathrm{FFM}_{\mathrm{BIA}}$ indifferent subgroups

*Denotes significantly different at the .05 level

The results were similar to the $\mathrm{BF} \%$-matched samples; the regression lines of $\mathrm{FFM}_{\mathrm{BIA}}$ against $\mathrm{FFM}_{\mathrm{DXA}}$ developed using randomly assigned data sets demonstrated a similar trend that deviated from an identical line (slope $=0.93$ for $G_{1}$ and 0.92 for $G_{2}$; data not shown).

When comparing the results of our predictive model with those of previously published studies on supineposition hand-to-foot BIA measurements, the correlation coefficient and SEE were similar to those of Kotler et al. [32] $\left(\mathrm{r}^{2}=0.83, n=256\right.$, SEE = approximately $\left.3.0 \mathrm{~kg}\right)$, Sun et al. [8] $\left(\mathrm{r}^{2}=0.92, n=1095\right.$, RMSE $\left.=2.9 \mathrm{~kg}\right)$, Heitmann et al. [40] $\left(\mathrm{r}^{2}=0.90, n=139, \mathrm{SEE}=3.6 \mathrm{~kg}\right)$, and Sun et al. [8] $\left(\mathrm{r}^{2}=90, \mathrm{n}=734, \mathrm{RMSE}=3.9 \mathrm{~kg}\right)$; however, they were lower than those of Kyle et al. [23] $\left(\mathrm{r}^{2}=0.96, n=343\right.$, $\mathrm{SEE}=1.8 \mathrm{~kg})$ and Deurenberg et al. [41] $\left(\mathrm{r}^{2}=0.92, n=661\right.$, $\mathrm{SEE}=2.6 \mathrm{~kg}$ ). These results may have been because the correlation coefficient of the predictive value and the measured FFM value tended to be higher in the hand-to-foot model than in the foot-to-foot model $[42,43]$; this may be a shortcoming of the foot-to-foot model in assessing FFM.

The Geneva BIA equation published by Kyle et al. [23] provides ideal results of a high $r^{2}$ and low SEE $\left(r^{2}=0.96\right.$, $\mathrm{LOA}=-3.4$ to $3.5 \mathrm{~kg}$, and $\mathrm{SEE}=1.72 \mathrm{~kg}$ ); however, their subjects' BMI range was narrower $\left(17.0-33.8 \mathrm{~kg} / \mathrm{m}^{2}\right)$ than that of the subjects in our study $\left(15.9-43.1 \mathrm{~kg} / \mathrm{m}^{2}\right)$. Sun et al. [20] and Deurenberg [44] indicated that the estimated results were affected by the level of adiposity. The developed predictive equations in our study overestimated FFM in subgroups with a higher BF\% (male, $\mathrm{BF} \%_{\text {DXA }}>30 \%$; female, $\left.\mathrm{BF} \%_{\text {DXA }}>40 \%\right)$. When these subjects were excluded and used to develop another model, then the results $\left(n=442 ; \mathrm{BMI}, 15.8-36.9 \mathrm{~kg} / \mathrm{m}^{2}\right.$; $\mathrm{r}^{2}=0.94 ; \mathrm{SEE}=2.80 \mathrm{~kg}, \mathrm{LOA}=$ not reported) were comparable with those reported by Kyle et al. [23]. Although these results may be appealing, they have limited application. We included subjects with a high BF\% to broaden the application range. The average $\mathrm{FFM}_{\mathrm{DXA}}$ of the subjects in our study was $50.17 \pm 11.25 \mathrm{~kg}$, while that in the Geneva BIA equation was $54.0 \pm 10.5 \mathrm{~kg}$. Their sample had a smaller SD for $\mathrm{FFM}_{\mathrm{DXA}}$, indicating that their data tended to be closer to the mean, resulting in a smaller SEE. The standing foot-to-foot impedance measurement may be convenient, but has a significantly smaller FFM correlation than the hand-to-foot impedance measurement $[31,42]$. Based on the estimate equation suggested in our study, the LOA may be large; however, we consider it acceptable. This is one of the limitations of the present study. When estimating FFM using 
our predictive equation in subjects with a high level of adiposity (female, $\mathrm{BF} \%_{\mathrm{DXA}}>40 \%$; male, $\mathrm{BF} \%_{\mathrm{DXA}}>30 \%$ ), the bias \pm SD in female and male subjects was $2.0 \pm 2.9$ and $2.1 \pm 3.2 \mathrm{~kg}$, respectively. Although the bias and SD were higher than those in the other leaner subgroups in our study, the results show that our predictive equations performed better for estimating FFM in subjects with a high $\mathrm{BF} \%$ than did the equation developed by Jakicic et al. [45] $\left(\mathrm{r}^{2}=0.66, \mathrm{SEE}=8.8 \mathrm{~kg}, n=123\right.$, and LOA = not reported $)$.

Age has not been included as a predictor in every model in other published studies [23, 36, 41]. Some models excluded age because it only explained limited variance in FFM [23]. However, in our predictive model, age explained approximately $18.0 \%$ of the variance in FFM and was therefore included in the predictive model. Several studies have indicated that the concentration of potassium in fat-free tissue decreases systematically with age $[46,47]$. There are important age-related changes in the composition of FFM. The main molecular components of the FFM are water, protein, osseous and nonosseous mineral, and glycogen. The proportion of water, protein, and osseous mineral in the FFM vary systematically with age. Kyle et al. [47] examined the accuracy of a predictive model with different age groups. Many studies have reported that the accuracy of BIA estimation is affected by the level of obesity [18-20]. Therefore, this study examined the accuracy of a model for predicting FFM in individuals with different percentages of body fat. The predictive value of FFM using our model was not significantly different from $\mathrm{FFM}_{\mathrm{DXA}}$ among the subgroups of different $\mathrm{BF} \%$ values and sexes, and the correlation coefficients were 0.87 $(p=0.92)$ in females and $0.89(p=0.97)$ in males. These results indicate that BIA is an accurate method for assessing FFM in individuals with a $\mathrm{BF} \%$ in the range evaluated in our study. Moreover, standing foot-to-foot BIA can be used as a convenient method to assess the different $\mathrm{BF} \%$ values in male and female adults. Clinical use of BIA in patients with abnormal hydration cannot be recommended until further validation has proven that a BIA algorithm is accurate in such conditions. The present study focused on the different foot-to-foot BIA BF\% values; we did not discuss differences in foot-to-foot BIA FFM estimate measurements based on either regional composition or different body types; these are topics requiring further discussion. Moreover, in patients with body shape abnormalities, very small or large body heights, or relative sitting heights, the use of prediction equations in subjects with an abnormal body build (e.g., acromegaly or amputation) should be interpreted with caution [48]. Many published studies on BIA estimate equations have used impedance as an estimate variable, but the present study applied the impedance variable in the standing foot-to-foot model and found satisfactory results for estimating FFM in a healthy Taiwanese population $\left(\mathrm{BMI}=16-43 \mathrm{~kg} / \mathrm{m}^{2}\right)$.

\section{Conclusions}

Our FFM predictive model based on standing foot-to-foot BIA can conveniently predict FFM in both male and female healthy Asian subjects with different $\mathrm{BF} \%$ values.

\section{Consent}

Written informed consent was obtained from the patient for the publication of this report and any accompanying images.

\section{Abbreviations}

BF\%: Body fat percentage; $\mathrm{H}$ : Height; $Z_{\mathrm{F}-\mathrm{F}}$ : Foot-to-foot impedance; W: Weight; y: Age; s: Sex; Xc: Reactance; R: Resistance; LOA: Limits of agreement.

\section{Competing interests}

The authors declare that they have no competing interests.

\section{Authors' contributions}

$\mathrm{ACH}, \mathrm{CLC}, \mathrm{CLL}$, and $\mathrm{LMC}$ interpreted the results and critically reviewed the manuscript; CSW designed the study and conducted the research; CLC, and $\mathrm{KCH}$ contributed to subject recruitment and data collection; GBD, LMC, $\mathrm{KCH}$ and $\mathrm{YLH}$ performed the laboratory analysis and statistical analysis, interpreted the results, and wrote the manuscript; YYC supervised the study; and all authors read and approved the final manuscript.

\section{Acknowledgements}

This study was supported by a grant (NSC 95-2413-H-028-003) from the National Science Council of the Republic of China. The authors thank Charder Electronic Co., Ltd. for participating in this study.

\section{Author details}

${ }^{1}$ Center for General Education, I-Shou University, No.1 Sec. 1, Syuecheng Rd., Dashu Dist, Kaoshiung City 84001, Taiwan. '2Department of Physical Education, National Taiwan Sport University, No. 16, Sec. 1, Shuang-Shih Road, Taichung City 404, Taiwan. ${ }^{3}$ Department of Radiology, Jen-Ai Hospital, No. 483, Don Long Road, Dali Dist, Taichung City 412, Taiwan. ${ }^{4}$ Department of Hotel, Restaurant, and Tourism Management, College of Business and Management, East Stroudsburg University of Pennsylvania, 200 Prospect St., East Stroudsburg, PA 18301, USA. ${ }^{5}$ Department of Exercise Science, College of Health Science, East Stroudsburg University of Pennsylvania, 200 Prospect St., East Stroudsburg, PA 18301, USA. ${ }^{6}$ Department of Applied Math, National Chung Hsing University, 250 Kuo Kuang Rd., Taichung City 402, Taiwan. 'Department of Leisure, Recreation and Tourism Management, Tzu-Hui Institute of Technology, No. 367, Sanmin Rd., Nanjhou Hsian, Pingtung County 926, Taiwan. ${ }^{8}$ Department of Physical Medicine and Rehabilitation, Taichung Hospital, Ministry of Health and Welfare, No. 199, Sec. 1, San-Min Road, Taichung City 403, Taiwan. ${ }^{9}$ Office of Physical Education and Sport, National Chung Hsing University, 250 Kuo Kuang Rd., Taichung City 402, Taiwan. ${ }^{10}$ Research Center, Charder Electronic Co., LTD, No. 103, Guozhong Rd., Dali Dist., Taichung City 412, Taiwan.

Received: 26 November 2014 Accepted: 11 May 2015

Published online: 19 May 2015

\section{References}

1. Nuñez C, Gallagher D, Visser M, Pi-Sunyer FX, Wang Z, Heymsfield SB Bioimpedance analysis: evaluation of leg-to-leg system based on pressure contact footpad electrodes. Med Sci Sports Exerc. 1997;29:524-31.

2. Tan YX, Nuñez C, Sun Y, Zhang K, Wang Z, Heymsfield SB. New electrode system for rapid whole-body and segmental bioimpedance assessment. Med Sci Sports Exerc. 1997;29:1269-73.

3. Elia M, Fuller NJ, Hardingham CR, Graves M, Screaton N, Dixon AK, et al. Modeling leg sections by bioelectrical impedance analysis, dual-energy $\mathrm{X}$-ray absorptiometry, and anthropometry: assessing segmental muscle volume using magnetic resonance imaging as a reference. Am NY Acad Sci. 2000;904:298-305.

4. Boneva-Asiova Z, Boyanov MA. Body composition analysis by leg-to-leg bioelectrical impedance and dual-energy $\mathrm{X}$-ray absorptiometry in non-obese and obese individuals. Diabetes Obes Meta. 2008;10:1012-8. 
5. Bosy-Westphal A, Later W, Hitze B, Sato T, Kossel E, Gluer CC, et al. Accuracy of bioelectrical impedance consumer devices for measurement of body composition in comparison to whole body magnetic resonance imaging and dual X-ray absorptiometry. Obes Facts. 2008;1:319-24.

6. Hosking J, Metcalf BS, Jeffery AN, et al. Validation of foot-to-foot bioelectrical impedance analysis with dual-energy $\mathrm{X}$-ray absorptiometry in the assessment of body composition in young children: the EarlyBird cohort. Br J Nutr. 2006;96:1163-8.

7. Hosking J, Metcalf BS, Jeffery AN, Voss LD, Wilkin TJ. Prediction of body cell mass, fat-free mass, and total body water with bioelectrical impedance analysis: effect of race, sex, and disease. Am J Clin Nutr. 1996;64:S489-97.

8. Sun SS, Chumlea WC, Heymsfield SB, Lukaski HC, Schoeller D, Friedl K, et al. Development of bioelectrical impedance analysis prediction equations for body composition with the use of a multicomponent model for use in epidemiologic surveys. Am J Clin Nutr. 2003;77:331-4.

9. Stolarczyk LM, Heyward VH, Hicks VL, Baumgartner RN. Predictive accuracy of bioelectrical impedance in estimating body composition of Native American women. Am J Clin Nutr. 1994;59:964-70.

10. Deurenberg P, Deurenberg-Yap M, Schouten FJ. Validity of total and segmental impedance measurements for prediction of body composition across ethnic population groups. Eur J ClinNutr. 2002;56:214-20.

11. Rush EC, Vhandu V, Plank LD. Prediction of fat-free mass by bioimpedance analysis in migrant Asian Indian men and women: a cross validation study. Int J Obes (Lond). 2006;30:1125-31.

12. Lazzer S, Boirie $Y$, Meyer M, Vermorel M. Evaluation of two foot-to-foot bioelectrical impedance analysers to assess body composition in overweight and obese adolescents. Br J Nutr. 2003;90:987-92.

13. Lukaski HC, Siders WA. Validity and accuracy of regional bioelectrical impedance devices to determine whole-body fatness. Nutrition. 2003;19:851-7.

14. Jaffrin MY, Kieffer R, Moreno MV. Evaluation of foot-to-foot impedance meter measuring extracellular fluid volume in addition to fat-free mass and fat-tissue mass. Nutrition. 2005;21:815-24.

15. Ritchie JD, Miller CK, Smicklas-Wright H. Tanita foot-to-foot bioelectrical impedance analysis system validated in older adults. J Am Diet Assoc. 2005; 105:1617-9.

16. Tyrrell VJ, Richards G, Hofman P, Gillies GF, Robinson E, Cutfield WS. Foot-to-foot bioelectrical impedance analysis: a valuable tool for the measurement of body composition in children. Int J Obes Relat Metab Disord. 2001;25:273-8.

17. Utter AC, Nieman DC, Ward AN, Butterworth DE. Use of the leg-to-leg bioelectrical impedance method in assessing body-composition change in obese women. Am J ClinNutr. 1999;69:603-7.

18. Gray DS, Bray GA, Gemayel N, Kaplan K. Effect of obesity on bioelectrical impedance. Am J Clin Nutr. 1989;50:255-60.

19. Fors H, Gelander L, Bjarnason R, Albertsson Wikland K, Bosaeus I. Body composition, as assessed by bioelectrical impedance spectroscopy and dual-energy X-ray absorptiometry, in a healthy pediatric population. Acta Paediatr. 2002;91:755-60.

20. Sun G, French CR, Martin GR, Younghusband B, Green RC, Xie YG, et al. Comparison of multifrequency bioelectrical impedance analysis with dual-energy for assessment of percentage body fat in large, healthy population. Am J Clin Nutr. 2005;81:74-8.

21. Powell JJ, Tucker $L$, Fisher AG, Wilcox K. The effects of different percentages of dietary fat intake, exercise, and calorie restriction on body composition and body weight in obese females. Am J Health Promot. 1994;8:442-8.

22. Kerlinger FN, Pedhazur EJ. Multiple regression in behavioral research. New York: Holt, Rinehard\& Winston; 1973.

23. Kyle UG, Genton L, Karsegard L, Slosman DO, Pichard C. Single prediction equation for bioelectrical impedance analysis in adults aged 20-94 years. Nutrition. 2001;17:248-53.

24. Bland JM, Altman DG. Statistical methods for assessing agreement between two methods of clinical measurement. Lancet. 1986;1:307-10.

25. Passing $\mathrm{H}$, Bablok W. A new biometrical procedure of testing the equality of measurements from two different analytical methods. Application of linear regression procedures for method comparison studies in clinical chemistry. Part I. J Cin Chem Clin Biochem. 1983;21:709-20.

26. Maw GJ, Mackenzie IL, Taylor NA. Redistribution of body fluids during postural manipulations. Acta Physiol Scand. 1995;155:157-63.

27. Rush EC, Crowley J, Freitas IF, Luke A. Validity of hand-to-foot measurement of bioimpedance: standing compared with Lying position. Obesity (Silver Spring). 2006;14:252-7.
28. Oshima Y, Shiga T. Within-day variability of whole-body and segmental bioelectrical impedance in a standing position. Eur J Clin Nutr. 2006;60:938-41.

29. Kushner RF, Gudivaka R, Schoeller DA. Clinical characteristics influencing bioelectrical impedance analysis measurements. Am J Clin Nutr. 1996;64(3 Suppl):423s-7.

30. Kyle UG, Bosaeus I, De Lorenzo AD, Deurenberg P, Elia M, Gómez JM, et al. Bioelectrical impedance analysis - part I: review of principles and methods. ClinNutr. 2004;23:1226-43.

31. Pietrobelli A, Rubiano F, St-Onge MP, Heymsfield SB. New bioimpedance analysis system: improved phenotyping with whole-body analysis. Eur J Clin Nutr. 2004;58(1):1479-84.

32. Kotler DP, Burastero S, Wang J, Pierson Jr RN. Prediction of body cell mass, fat-free mass, and total body water with bioelectrical impedance analysis: effects of race, sex, and disease. Am J Clin Nutr. 1996;64(3 suppl):489s-97.

33. Lukaski HC, Johnson PE, Bolonchuk WW, Lykken Gl. Assessment of fat-free mass using bioelectrical impedance measurements of the human body. Am J Clin Nutr. 1985;41:810-7.

34. Chumlea WC, Guo SS. Assessment and prevalence of obesity: application of new methods to a major problem. Endocrine. 2000;13:135-42.

35. Chumlea WC, Guo SS, Kuczmarski RJ, Johnson CL, Leahy CK. Reliability for anthropometry in the Hispanic health and nutrition examination survey (HHANNES 1982-1984). Am J Clin Nutr. 1990;51:S902-7.

36. Deurenberg P, van der Kooij K, Evers P, Hulshof T. Assessment of body composition by bioelectrical impedance in a population aged $>60 \mathrm{y}$. Am J Clin Nutr. 1990;51:3-6.

37. Stewart SP, Bramley PN, Heighton R, et al. Estimation of body composition from bioelectrical impedance of body segments: comparison with dual-energy X-ray absorptiometry. Br J Nutr. 1993;69:645-55.

38. Guo SS, Chumlea WC, Cockram DB. Use of statistical methods to estimate body composition. Am J Clin Nutr. 1996;64:S 428S-S435.

39. Cohen J. Statistical power analysis for the behavioral sciences. 2nd ed. New York: Academic; 1988.

40. Heitmann BL. Prediction of body water and fat in adult Danes from measurement of electrical impedance. A validation study. In J Obes. 1990;14:789-802.

41. Deurenberg P, van der Kooy K, Leenen R, Weststrate JA, Seidell JC. Sex and age specific prediction for estimating body composition from bioelectrical impedance: a cross-validation study. Int J Obes. 1991;15:17-25.

42. Hsieh KC, Lu HK, Chen CH, Jang TR, Chen YY, Kao MF. The validity and accuracy in foot-to-foot bioelectrical impedance analysis measuring models referenced by dual-energy $\mathrm{X}$-ray absorptiometry in body composition in standing position. Afr J Biotech. 2011;10:3222-31.

43. Bousbiat S, Jaffrin MY, Dongmo E. Comparison of body fat-free masses calculated from hand-to-foot and foot-to-foot resistances with DXA measurements. Med Bio Eng Comput. 2011;49:1329-36.

44. Deurenberg P. Limitations of the bioelectrical impedance method for the assessment of body fat in sever obesity. Am J Clin Nutr. 1996;64S:449S-52.

45. Jakicic JM, Wing RR, Lang W. Bioelectrical impedance analysis to assess body composition in obese adult women: the effect of ethnicity. Int J Obes Relat Disord. 1998;22:243-9.

46. Cohn SH, Vaswani A, Zanzi I, Aloia JF, Roginsky MS, Ellis KJ. Changes in body chemical composition with age measured by total body neutron activation. Metabolism. 1976;25:85-95.

47. Kehayias JJ, Fiatarone MA, Zhuang H, Roubenoff R. Total body potassium and body fat: relevance to aging. Am J Clin Nutr. 1997;66:904-10.

48. Kyle UG, Bosaeus I, De Lorenzo AD, Deurenberg P, Elia M, Manuel Gómez J, et al. Bioelectrical impedance analysis - part II: utilization in clinical practice. Clin Nutr. 2004;23:1430-53. 